\title{
MODELO LÓGICO DA INFORMAÇÃO ARQUIVADA NO OPEN ARCHIVAL INFORMATION SYSTEM: UMA REFLEXÃO ARQUIVÍSTICA
}

\begin{abstract}
Resumo: a constante produção de documentos digitais no âmbito da Arquivística ocasionou um processo de revisão teórico-prático. Como consequência, além de custodiar documentos analógicos, os arquivos passaram também, a custodiar documentos digitais. No entanto a sua preservação é dotada de complexidades tecnológicas e especificidades arquivísticas, e para sanar tais necessidades, tem-se discutido a implementação de políticas, estratégias e repositórios digitais em conformidade com o modelo Open Archival Information System (OAIS). Para fins deste estudo, aborda-se o modelo lógico da informação arquivada, proposto pelo OAIS, com o objetivo de identificar e apontar convergências com a Arquivística. A metodologia consiste no levantamento bibliográfico composto por livros, publicações técnicas e artigos científicos, caracteriza-se assim, como um artigo de revisão assistemática. Como resultado, observaram-se convergências entre a Arquivística e o modelo lógico da informação arquivada presente no OAIS em relação à organicidade, proveniência, custódia e acesso. Dentre os principais apontamentos, ressalta-se a pertinência do modelo lógico da informação arquivada, o qual proporciona confiabilidade aos documentos arquivísticos custodiados, e assim reforça a possibilidade de implementar repositórios arquivísticos digitais confiáveis, em conformidade com o OAIS.
\end{abstract}

Palavras-chave: Preservação digital. Documento arquivístico digital. Repositório digital. OAIS. Arquivística.

\author{
Henrique Machado dos Santos \\ Mestre em Patrimônio Cultural pela \\ Universidade Federal de Santa Maria. \\ Arquivista da Coordenação de Arquivo \\ Geral da Universidade Federal do Rio \\ Grande. \\ henrique.hms.br@gmail.com
}

Daniel Flores

Doutor em Metodologías y Líneas de Investigación en Biblioteconomía y

Documentación pela Universidad de

Salamanca

Pós-Doutorado financiado pela Fundación Carolina/Universidad de Salamanca na Espanha em Documentos

Digitais

Docente Permanente do PPGCI da UFF dfloresbr@gmail.com

\section{LOGICAL MODEL OF ARCHIVED INFORMATION IN THE OPEN ARCHIVAL INFORMATION SYSTEM: AN ARCHIVAL SCIENCE REFLECTION}

\begin{abstract}
: the constant production of digital records within the archives gave rise to a process of theoretical-practical revision. As consequence, in addition to guarding analog records, the archives also passed, to guard digital records. However, its preservation is endowed with technological complexities and archival specificities, and to address such needs, we have discussed the implementation of policies, strategies and digital repositories in accordance with the Open Archival Information System (OAIS) model. For the purposes of this study, is presented the logical model of archived information, proposed by the OAIS, with the aim of identifying and pointing out convergences with Archival science. The methodology consists of a bibliographical survey composed of books, technical publications and scientific articles, characterized as an article of no systematic review. As a result, we observed convergences between Archival science and the logical model of archived information present in OAIS in relation to organicity, provenance, custody and access. Among the main notation, the relevance of the logical model of archived information, which provides reliability to the archived records, is emphasized, and thus reinforces the possibility of reliable digital archival repositories in accordance with OAIS.
\end{abstract}

Keywords: Digital preservation. Digital archival record. Digital repository. OAIS. Archival science. 


\section{INTRODUÇÃO}

A profusão de documentos digitais produzidos no âmbito da Arquivística/Arquivologia tornou necessário um processo de reformulação teórico-prático a fim de contemplar: as especificidades de um documento arquivístico digital e a complexidade do ambiente digital. Com isso, surgiram diversos estudos que retratam aspectos relacionados à preservação digital, manutenção da autenticidade e garantia de acesso contínuo em longo prazo. Assim, as discussões em torno das políticas, das estratégias e da implementação de repositórios digitais se acentuaram, e já constituem um arcabouço teórico sobre a preservação digital.

A política de preservação, em nível institucional, é entendida como a primeira etapa a ser realizada, e considerada a ação mais efetiva para evitar as perdas. Assim, torna-se fundamental utilizar padrões amplamente aceitos, avaliar os suportes e as ferramentas de replicação que serão utilizadas, e identificar os riscos para evitá-los ou minimizá-los. Além do mais, as regras e os requisitos dos sistemas devem ser definidos por profissionais das Tecnologias da Informação e Comunicação (TIC's). O foco nas políticas se justifica, pois o problema da preservação não é resolvido por uma tecnologia, e sim pelo planejamento, ao estabelecer o compromisso de longa duração, e investimentos expressivos. Observa-se que a dependência da informação digital gera a necessidade de preservação, e o interrelacionamento de recursos e conhecimentos de profissionais de diversas áreas contribuirá para a efetividade das ações. Logo, ressalta-se que a preservação de documentos arquivísticos digitais requer ações arquivísticas em todo o ciclo vital inclusive antes de sua criação (BRASIL, 2004; 2015; CASANOVAS, 2008; FERREIRA, 2006; INNARELLI, 2009; 2011; 2012a; 2012b; MÁRDERO ARELLANO, 2004; SANTOS; FLORES, 2015b; SCHÄFER; CONSTANTE, 2012).

As estratégias, definidas a priori na política, consistem em intervenções necessárias para garantir a preservação e o acesso aos documentos. Observa-se que há diversas estratégias, que possuem foco em um determinado nível de preservação do objeto digital. $\mathrm{O}$ refrescamento tem foco na preservação do nível físico. A preservação de tecnologia, a emulação e o encapsulamento têm foco no nível lógico. Já a pedra de Rosetta digital e a migração focam-se no nível conceitual. No entanto, nenhuma das estratégias é capaz de resolver os problemas da obsolescência tecnológica de forma isolada, pois todas têm diversas 
vantagens e desvantagens. Impreterivelmente, é preciso implementar um conjunto de estratégias de preservação, conforme as peculiaridades da documentação (ALMEIDA; CENDÓN; SOUZA, 2012; BODÊ, 2007; CASANOVAS, 2008; FERREIRA, 2006; GRANGER, 2000; HEDSTROM, 2001; INNARELLI, 2009; MÁRDERO ARELLANO, 2004; ROTHENBERG, 1999, SANTOS, 2005; 2012; SARAMAGO, 2002; SAYÃO, 2010a; SCHÄFER; CONSTANTE, 2012; SMITH, 2000; THIBODEAU, 2002; THOMAZ; SOARES, 2004).

Além de definir uma política institucional e selecionar o grupo de estratégias, a implementação de um repositório digital em conformidade com o modelo OAIS tornou-se uma necessidade. As políticas institucionais recomendam um ambiente confiável suficiente para manter a autenticidade, garantir a preservação e o acesso contínuo em longo prazo. Neste ambiente serão implementadas as estratégias e as demais ações necessárias, como, por exemplo, acréscimo de metadados, verificações de erros, detecção de vírus e negociação de direitos de acesso (BRASIL, 2015; DAY, 2004; FERREIRA, 2006; HEDSTROM, 2001; MÁRDERO ARELLANO, 2004; SARAMAGO, 2004; SAYÃO, 2010a; SOUZA; OLIVEIRA; D'AVILA; CHAVES, 2012; THOMAZ, 2006; 2007; THOMAZ; SOARES, 2004).

Tendo em vista o exposto, ressalta-se que as discussões sobre políticas, estratégias e repositório estão longe de serem encerradas. Mesmo assim, há um consenso de sua necessidade, concatenando, um corpus teórico especializado, que se delega à preservação de documentos digitais.

O modelo OAIS tornou-se suficientemente difundido, no entanto, os seus fluxos de informação e a forma com que estrutura os documentos e as informações relacionadas é complexa. Logo, surge a necessidade de estudos que aprofundem e descrevam o seu funcionamento no âmbito da Arquivística, especialmente no que tange às suas funções de descrição e acesso, bem como, seus princípios da proveniência e organicidade.

Dessa forma, o presente estudo tem por objetivo analisar o modelo lógico da informação arquivada no OAIS, tendo como pano de fundo a preservação de documentos arquivísticos digitais em longo prazo. Para isso, são perpassados aspectos relacionados ao objeto de dados, ao objeto de informação, a informação de representação e a taxonomia dos objetos. 
A metodologia utilizada parte do levantamento bibliográfico de materiais previamente publicados, que contempla: livros, publicações técnicas e artigos de periódicos científicos recuperados pela ferramenta Google Scholar. A seleção dos artigos contempla o período entre 1998 e 2018, de modo que parte das seguintes palavras-chave: "preservação de documentos digitais", "estratégias de preservação digital", "documentos arquivísticos digitais", "repositórios digitais confiáveis" e "digital preservation". Logo, buscou-se obter um panorama da preservação digital no que tange às políticas, estratégias e repositórios. Por fim, esta revisão assistemática visa proporcionar uma reflexão sobre o tema, e salientar o ponto de vista dos autores no que se refere à relação existente entre o modelo lógico da informação arquivada pelo OAIS e a sua implementação no contexto da Arquivística (GIL, 2010; LUNA, 1997; SILVA; MENEZES, 2005).

\section{DO OBJETO DE DADOS AO OBJETO DE INFORMAÇÃO}

O objeto de dados (data object) pode ser um objeto físico (physical object) ou um objeto digital (digital object), associado a uma informação de representação (representation information) que lhe concebe sentido. Desta forma, após o objeto de dados ser interpretado com o auxílio da informação de representação, obtêm-se um objeto de informação (information object) (ABNT, 2007; CCSDS, 2012; ISO 14721:2012). A seguir, a "Figura 1 Estrutura do objeto de informação" apresenta tais componentes.

Figura 1 - Estrutura do objeto de informação

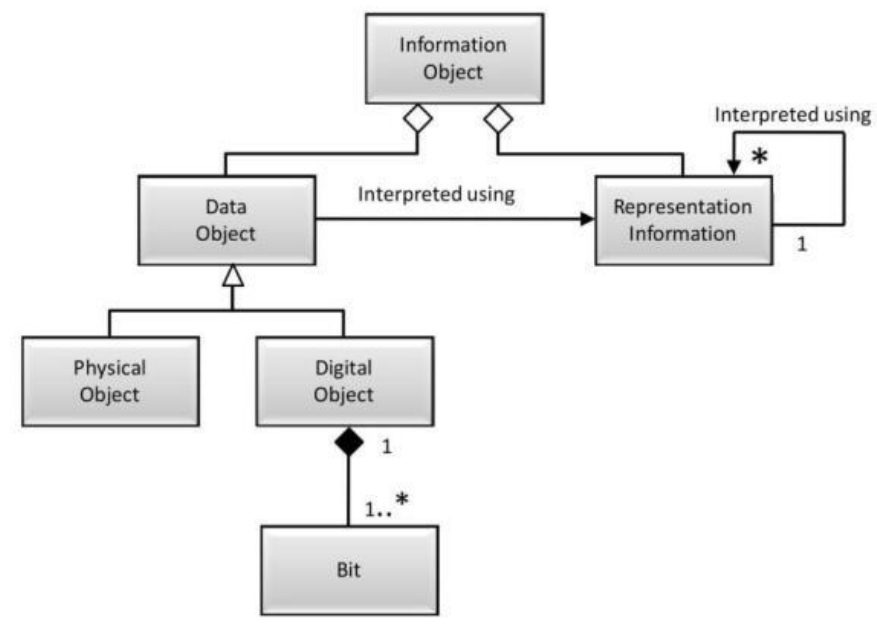

Fonte: (CCSDS, 2012, p. 4-21). 
Nessa relação, observa-se que uma sequência de bits (bit) irá compor o objeto digital, já o objeto físico será composto por um objeto analógico, como, por exemplo, uma rocha lunar ou um relatório impresso. Assim, objeto físico e objeto digital irão compor o objeto de dados, e para ser preservado e corretamente interpretado, será necessário adicionar a informação de representação.

No ambiente informático, os objetos digitais representam documentos específicos com significado apenas para o software que os criou. Portanto, a sequência de bits precisa ser interpretada, pois é capaz de representar qualquer coisa (MÁRDERO ARELLANO, 2004). Sendo assim, no modelo OAIS, a informação de representação auxilia na interpretação da sequência de bits do objeto digital e na compreensão do objeto físico, fornecendo análises e relatórios relacionados, que lhes conferem significado adicional.

Um objeto digital aparentemente uniforme e simples contém diversos componentes digitais. E por vezes, alguns são dependentes até mesmo do próprio sistema operacional, como, por exemplo, as fontes de um documento textual (BARBEDO, 2005). Logo, um documento digital pode ser composto por diversos tipos de objetos digitais (INNARELLI, 2009).

É importante esclarecer que o documento arquivístico digital é o objeto conceitual, isto é, aquele normalmente apresentado em dispositivo de saída (monitor, caixa de som), e não o objeto físico (as cadeias de bits registradas em um suporte). As cadeias de bits são necessárias para que o documento arquivístico seja apresentado, mas não se constituem nesse documento (BRASIL, 2012, p. 2).

Dessa forma, tem-se como meta, preservar o objeto de dados e a sua respectiva informação de representação, a fim de reunir todas as informações necessárias para preservar e compreender o significado do objeto físico e/ou do objeto digital. Assim, obtém-se o objeto de informação, que pode ser entendido como o documento arquivístico digital com alguma informação adicional que complementa o seu significado.

\section{INFORMAÇÃO DE REPRESENTAÇÃO}

A informação de representação do objeto físico adiciona significado sobre fatores observáveis. No caso do objeto digital, a informação de representação mapeia os bits em tipos 
de dados conhecidos, agrupando-os, e posteriormente, associa este mapeamento a significados de alto nível (ABNT, 2007; CCSDS, 2012; ISO 14721:2012).

\subsection{TIPOS DE INFORMAÇÃO DE REPRESENTAÇÃO}

O objeto digital é composto de uma ou mais sequências de bits, que poderão, juntamente com o objeto físico, compor o objeto de informação. Por sua vez, o objeto de informação irá converter as sequências de bits em informações significativas.

A informação de representação indica se um determinado fluxo de bits representa, por exemplo, um parágrafo de texto, um som ou uma imagem. Entretanto, esse conhecimento pode ser insuficiente para interpretar o conteúdo (SARAMAGO, 2004). Para isso, descrevemse o formato ou conceitos de estrutura de dados que serão aplicados às sequências de bits, definidos como informação estrutural do objeto de informação de representação que é necessária para interpretar o objeto de dados (ABNT, 2007; CCSDS, 2012; ISO 14721:2012).

A informação estrutural interpreta os bits organizados com significados de alto nível. Portanto, deve incluir especificações sobre o formato dos dados, e se possível, uma descrição da plataforma de hardware e software em que os dados foram criados, pois isso é essencial para garantir o acesso a posteriori (SARAMAGO, 2004). No entanto, o conteúdo fornecido pela informação estrutural (structure information) raramente é suficiente à informação representação, sendo necessária uma informação adicional, então denominada de informação semântica (semantic information) (ABNT, 2007; CCSDS, 2012; ISO 14721:2012).

A informação semântica, por sua vez, tem a função de acrescentar significado à estrutura dos dados, que é identificada por intermédio da informação estrutural. Sendo assim, a informação estrutural pode identificar uma informação textual codificada em código American Standard Code for Information Interchange (ASCII) ${ }^{1}$ enquanto a informação semântica pode indicar que o texto está escrito em inglês (SARAMAGO, 2004). Observa-se que a informação estrutural e a informação semântica possuem objetivos distintos, porém são complementares; de modo a reunir informações necessárias para conferir sentido, não se limitando apenas em preservar as sequências de bits.

\footnotetext{
${ }^{1}$ Criado com objetivo de padronizar os códigos para caracteres alfanuméricos para que computadores de diferentes fabricantes conseguissem interpretá-lo.
} 
Logo, a informação de representação irá conter basicamente: informação estrutural e informação semântica. Em algumas implementações essa distinção é subjetiva, visto a possibilidade de haver diversos e complexos inter-relacionamentos entre informação estrutural e informação semântica (ABNT, 2007; CCSDS, 2012; ISO 14721:2012). A seguir a "Figura 2 - Objeto de informação de representação" apresenta tais componentes e seus respectivos subtipos.

Figura 2 - Objeto de informação de representação

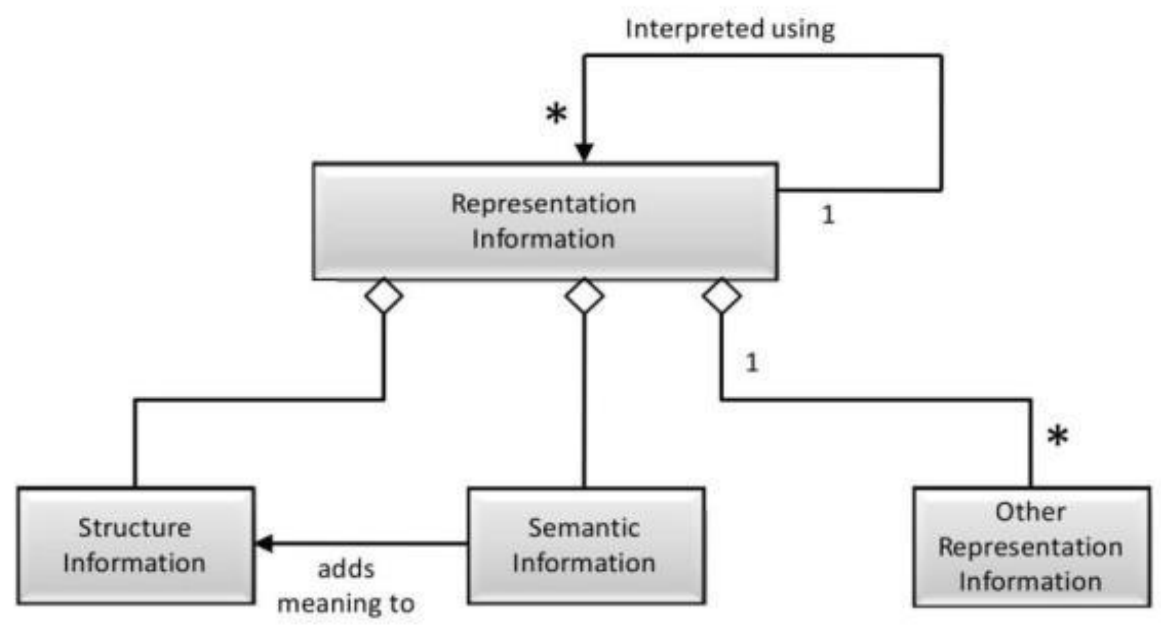

Fonte: (CCSDS, 2012, p. 4-23).

$\mathrm{Na}$ figura observa-se ainda, que a informação de representação (representation information) poderá conter referências a outras informações de representação (other representation information). Dentre essas, cita-se, por exemplo, softwares, algoritmos ou instruções, os quais sejam necessários à compreensão do conteúdo do objeto de dados. Isso se dá em razão do caráter recursivo da informação digital, tendo como consequência a necessidade de cada vez mais informações digitais para representar uma determinada informação digital.

As outras informações de representação são determinadas como parte da informação de representação, embora não sejam de ordem semântica ou estrutural (ABNT, 2007; CCSDS, 2012; ISO 14721:2012). Trata-se de um tipo de informação de representação "complementar". 
Tais complexidades ressaltam que a dificuldade fundamental da preservação digital é implícita à própria natureza dos objetos digitais que se pretende preservar. Pelo fato de que são acessíveis, tão somente, por combinações específicas entre os componentes de hardware, software, suporte e conhecimento técnico (THOMAZ; SOARES, 2004). Isso demonstra a fragilidade dos documentos arquivísticos em ambiente digital, e torna necessária a implementação de padrões como o OAIS. Em seu modelo de informação arquivada, o OAIS considera tais vulnerabilidades, e assim, propõem medidas preventivas, como a adição da informação de representação.

Os documentos digitais, diferentemente dos analógicos, podem ser facilmente decompostos em diversos elementos individuais, de modo que serão necessários maiores esforços para a preservação do "todo" (THOMAZ; SOARES, 2004). A anatomia de um documento arquivístico digital permite vislumbrar a necessidade de manter uma série de objetos digitais para garantir a sua correta interpretação, preservação e autenticidade. Portanto, a informação de representação eleva as perspectivas de manutenção da autenticidade e garantia de acesso contínuo em longo prazo, mesmo sem apresentar uma solução definitiva.

A interpretação da sequência de bits depende do conhecimento sobre como o objeto digital foi codificado, e neste ponto, há um entrave: uma sequência de bits não pode ser totalmente autodescritiva, pois qualquer descrição que seja codificada em bits deve ser interpretada em si mesma. Assim, o único método de realizar este processo é incluir descrições, facilmente legíveis, para cada objeto digital, que expliquem como interpretar a sua sequência de bits (ROTHENBERG, 1999). Logo, a informação de representação proposta pelo OAIS assume a tarefa de explicar como se interpreta a sequência de bits do objeto digital. Além disso, propõe um subtipo de informação de representação agregada para interpretar a si mesma.

Observa-se que a informação de representação é um objeto de informação que poderá ter o seu próprio objeto de dados e suas próprias informações de representação associadas conforme a relação do ciclo: interpretado usando (interpreted using). Por consequência, o conjunto resultante de objetos, pode ser denominado como parte de uma rede de representação (representation network) (ABNT, 2007; CCSDS, 2012; ISO 14721:2012). 


\subsection{REDE DE REPRESENTAÇÃO}

A informação de representação é um subtipo do objeto de informação que poderá ser expresso em formatos físicos ou digitais. Caso seja digital, será necessária uma informação de representação adicional para compreender a sequência de bits da informação de representação. Embora a informação de representação seja usada para adicionar significado, ela também poderá necessitar, paradoxalmente, de uma informação para ser representada. Tal dependência é típica da natureza digital, o que força um nível exaustivo de descrição, com padrões amplamente aceitos.

Para preservar um objeto digital é preciso ter capacidade de identificar e recuperar todos os seus componentes digitais, que podem ser objetos lógicos e físicos, necessários para representação do objeto conceitual; que pode ser reconhecido e compreendido por seres humanos. Portanto, esses componentes não se limitam, tão somente, aos objetos que contém os conteúdos dos documentos, de modo que podem incorporar dados necessários à estrutura ou apresentação do objeto conceitual (THIBODEAU, 2002).

Observa-se que cada item da informação de representação pode ter vários componentes, incluindo suas respectivas informações de representação. Dessa forma, para preservar o significado de um objeto de informação é preciso preservar a sua informação de representação; a qual é facilitada quando for expressa em formatos de simples compreensão. Com isso, ao se optar pela descrição textual é preciso atentar para o uso de linguagens padronizadas de descrição, suficientes para descrever a estrutura de dados (ABNT, 2007; CCSDS, 2012; ISO 14721:2012).

Além de identificar e recuperar os componentes digitais é fundamental processá-los corretamente. Para acessar um documento digital, as sequências de bits devem ser interpretadas como objetos lógicos, e posteriormente, apresentadas como objetos conceituais. Portanto, a preservação digital não se limita à preservação de objetos físicos, mas sim em preservar a capacidade de reproduzir os objetos. A preservação digital e o acesso ao objeto são questões inseparáveis, pois não se pode provar que um objeto foi preservado até que ele seja recriado, de forma apropriada, para ser plenamente interpretado por humanos ou por aplicações em sistemas informatizados (THIBODEAU, 2002). Assim, um repositório em conformidade com o OAIS terá de gerenciar questões relacionadas à capacidade de reunir 
informação de representação suficiente aos objetos de dados, para que assim, possa preservar e tornar os objetos de informação acessíveis.

No entanto, a inobservância do contexto em que se situa o público-alvo será determinante na geração de informações de má qualidade, e consequentemente, ocasionar graves problemas (DE SORDI, 2008). Por conseguinte, na medida em que a base de conhecimento da comunidade designada evoluir surgirá a necessidade de manter sua equivalência com a rede de representação.

A comunidade designada está situada no epicentro da evolução tecnológica, de modo que seu conhecimento dificilmente se mantém estagnado. Isso quer dizer que a comunidade designada expande seus conhecimentos em um continuum que segue as demandas tecnológicas, fato que inclui mudanças nos formatos de arquivo, nas mídias de armazenamento, e nas plataformas de hardware e software.

Não há identidade estável na informática porque os computadores, longe de serem os exemplares materiais de uma imutável ideia platônica, são redes de interfaces abertas a novas conexões, imprevisíveis, que podem transformar radicalmente seu significado e uso. $\mathrm{O}$ aspecto da informática mais determinante para a evolução cultural e as atividades cognitivas é sempre o mais recente, relaciona-se com o último envoltório técnico, a última conexão possível, a camada de programa mais exterior (LÉVY, 2010, p. 103).

A mutabilidade proporcionada pelo ambiente digital é uma vulnerabilidade implícita às ações de preservação digital. Isso reforça a necessidade de reunir informações de representação, bem como desenvolver ações e buscar alternativas para garantir a preservação e o acesso aos documentos digitais.

No OAIS, além da informação de representação, podem existir outros dois tipos especiais de informação que auxiliam na compreensão da informação de conteúdo: o software de apresentação e o software de acesso. O software de apresentação é capaz de exibir a informação de representação em formatos compreensíveis. Já o software de acesso irá apresentar parte ou toda a informação de conteúdo do objeto de informação, de modo compreensível para pessoas ou sistemas.

Observa-se ainda que, alguns casos há possibilidade de usar softwares de acesso para substituir a informação de representação, entretanto esta é uma prática complexa, visto a necessidade de um software que possua código aberto. Caso contrário, um software 
proprietário e/ou de código fechado pode ser um empecilho considerável à preservação, em virtude de uma série de restrições legais, além é claro, dos problemas ocasionados pela sua própria obsolescência tecnológica.

O uso de softwares específicos ou padrões fechados dificulta as ações de preservação digital, já que o responsável pela custódia não tem nenhum domínio sobre os tipos de objetos digitais armazenados (INNARELLI, 2009). Com isso, cria-se uma dependência em relação ao desenvolvedor, além de restringir a possibilidade de se reconstruir o software em caso de obsolescência (SANTOS; FLORES, 2018).

\begin{abstract}
O uso de software proprietário e de código fechado implica em uma série de restrições com relação ao acesso a sua estrutura interna fator que pode inviabilizar o ciclo de preservação. O software fechado não permite acesso ao código fonte, o que dificulta a reconstrução dos formatos de arquivo gerados, bem como a própria aplicação de software. Já o software proprietário necessita da aquisição de licenças de uso, fator que encarece o plano de preservação digital, e dependendo da variedade de softwares tornaria o plano financeiramente inviável (SANTOS; FLORES, 2015a, p. 93).
\end{abstract}

Em resumo, a informação de representação mediada por softwares possibilita praticidade com relação ao acesso imediato. Entretanto, além de ser um objeto complexo, o software poderá tornar-se obsoleto em longo prazo. Logo, o ideal é que a informação de representação seja registrada por meio de padrões simples e amplamente conhecidos. Caso seja necessário usar um software como informação de representação, este deverá possuir código aberto para possibilitar a sua reconstrução no futuro em caso de obsolescência.

\title{
4 TAXONOMIA DAS CLASSES DE OBJETOS DE INFORMAÇÃO
}

Há diversos tipos de informação que podem ser usados no OAIS, dentre esses: informação de conteúdo, informação descritiva de preservação, informação de empacotamento, informação descritiva, informação de representação e outros possíveis. A seguir, a "Figura 3 - Taxonomia do objeto de informação" apresenta os tipos de informação mais comuns no OAIS. 
Figura 3 - Taxonomia do objeto de informação

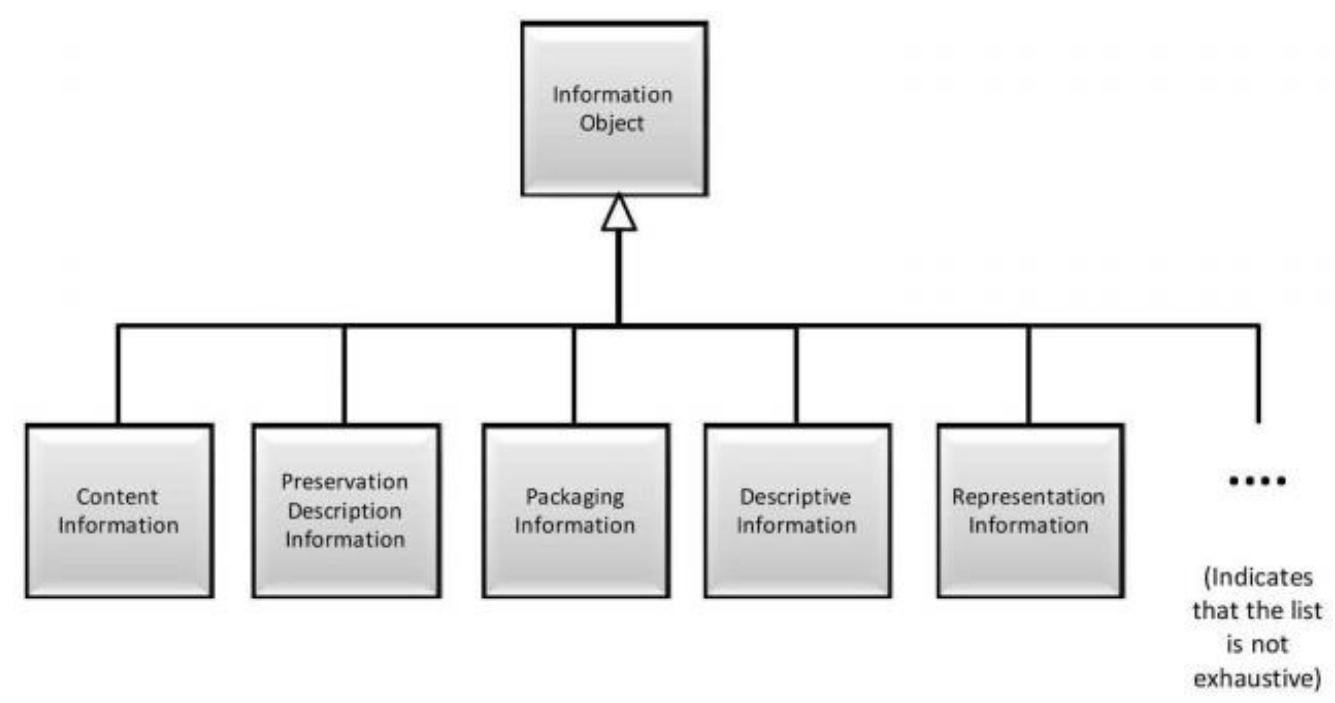

Fonte: (CCSDS, 2012, p. 4-26).

Na figura, observa-se que a lista de subtipos de informação não é exaustiva, logo, podem existir diversos outros tipos de objeto de informação. Assim, cada tipo de objeto de informação terá uma finalidade específica no OAIS.

\subsection{INFORMAÇÃO DE CONTEÚDO}

A informação de conteúdo (content information) é o conjunto original de informações considerado como meta de preservação no OAIS. Entretanto, decidir o que é a informação de conteúdo, é uma tarefa complexa, que poderá exigir negociações com o produtor. Sendo esta, uma decisão de execução e de organização, relacionada à forma com que os objetos de dados são admitidos e armazenados no OAIS.

Conforme a figura 3, a informação de conteúdo é essencialmente, um subtipo do objeto de informação. Ou seja, a informação de conteúdo é um objeto de dados de conteúdo contendo informação de representação (ABNT, 2007; CCSDS, 2012; ISO 14721:2012). Quaisquer tipos de objetos digitais usados pelo OAIS terão uma informação de representação para auxiliar na interpretação do próprio objeto, no entanto este detalhamento é por vezes omitido para simplificar a explicação e facilitar o seu entendimento. 
Observa-se que cada um desses objetos de dados terá a sua própria informação de representação; além disso, poderá ter informação de representação adicional para descrever os objetos de dados relacionados. Logo, a informação de representação de um objeto de dados de conteúdo digital (semântica ou sintática) é necessária para transformar os bits em informação de conteúdo (ABNT, 2007; CCSDS, 2012; ISO 14721:2012).

A qualidade de uma informação requer dados completos, os quais sejam transformados em informações, por meio de um processo eficiente (SILVA, 2003). Neste sentido, observa-se que o OAIS busca manter informações de conteúdo, com elevados níveis de qualidade, prova disso, é o uso da informação de representação. A ausência de informação de representação, ou mesmo a sua insuficiência, podem causar a perda do acesso às informações de conteúdo, tão logo, seria impossível preservar um determinado documento arquivístico digital.

Na prática, o OAIS necessita ter informação de representação suficiente, associada aos bits do objeto de dados de conteúdo, para que assim, possa assegurar que os membros da comunidade designada podem entrar na rede de representação com conhecimento suficiente para interpretar as informações de representação com precisão. Entretanto, esse é um risco significativo ao OAIS, especialmente para comunidades designadas especializadas, visto que os termos técnicos mais gerais podem ser de curta duração (ABNT, 2007; CCSDS, 2012; ISO 14721:2012). Logo, é preciso garantir a evolução natural da base de conhecimento da comunidade designada, para que assim não ocorra perda das informações de conteúdo.

As informações necessárias serão inseridas nos pacotes de software usados pela comunidade designada para apresentar e analisar as informações de conteúdo. A razão para preservar o funcionamento do software de acesso é um fator de conveniência. Isto porque mesmo com um conjunto completo de informação de representação, o acesso à totalidade ou parte de um objeto de dados de conteúdo digital requer o uso do software de acesso (ABNT, 2007; CCSDS, 2012; ISO 14721:2012).

Pode-se dizer que a informação de representação por si só, identifica e reúne todo o material necessário para a correta interpretação e respectiva compreensão da informação de conteúdo pela comunidade designada. No entanto, somente será possível obter acesso por meio do software interpretador, pois este atua de forma objetiva e imediata. Já a informação de representação, consiste em um conjunto de descrições que possibilitam encontrar um 
caminho confiável para recuperação da informação de conteúdo em qualquer contexto temporal ou tecnológico.

O uso do software de acesso para substituir as redes de representação é pertinente se for considerada a questão de minimizar os recursos necessários para processar dados e fornecer acesso aos usuários. Entretanto, a dependência por softwares específicos pode gerar grandes problemas à preservação de longo prazo, em virtude de sua consequente obsolescência tecnológica. Logo, sua preservação requer uma descrição completa e compreensível das informações de representação.

Preservar a informação nos formatos digitais mais simples possíveis irá minimizar os requisitos e a necessidade de um sofisticado software de recuperação. Consequentemente, a informação digital poderá ser transferida por meio de sucessivas gerações de tecnologia em um formato considerado "independente de softwares" como, por exemplo, arquivos de texto ASCII ou arquivos com estruturas simples e uniformes (HEDSTROM, 1998).

A estratégia de usar formatos digitais simples na preservação tem por objetivo ser aplicada para todos os documentos digitais produzidos. Entretanto, o uso originalmente proposto para esta estratégia pode ser considerado utópico em virtude da crescente evolução da complexidade dos formatos digitais. Mesmo assim, tais ideias ainda são válidas, principalmente quando comparadas a informação de representação. No OAIS, a informação de representação prioriza formatos simples para fornecer significado adicional à informação de conteúdo, e formatos ainda mais simples, até mesmo referenciados por um objeto físico, para interpretar a si mesma. Logo, a estratégia de usar formatos digitais simples é essencialmente pertinente, para simplificar a informação de representação.

Conforme o modelo OAIS é importante decidir quais partes da informação de conteúdo que formam o objeto de dados de conteúdo e quais partes que formam a informação de representação. Este aspecto é fundamental para compreender claramente o que está sendo preservado (ABNT, 2007; CCSDS, 2012; ISO 14721:2012). A identificação da informação do conteúdo junto aos seus objetos de informação de representação pode ser abordada por meio de cinco etapas:

a) Primeira etapa: identificar os bits da informação de conteúdo que compõem o objeto de dados; 
b) Segunda etapa: identificar um objeto de representação da informação que, de alguma forma, possa tratar os bits do objeto de dados de conteúdo e converta-os em informações mais significativas;

c) Terceira etapa: ao identificar o objeto de representação da informação, examinar o seu conteúdo para verificar se há objetos de informação de representação adicionais. Caso existam, é preciso obter os objetos de informação de representação necessários. Este processo deverá ser repetido até que não sejam mais encontrados objetos de representação de informação adicionais;

d) Quarta etapa: para cada objeto de informação de representação abordado na terceira etapa, deve-se identificar um objeto de informação de representação necessário, e repetir a terceira e a quarta etapa, até que não sejam identificados novos objetos de informação de representação;

e) Quinta etapa: como resultado, as informações de conteúdo consistem no objeto de dados de conteúdo e em cada um dos objetos de informação de representação identificados na segunda e na quarta etapa (ABNT, 2007; CCSDS, 2012; ISO 14721:2012).

A identificação da informação de conteúdo e da respectiva informação de representação é realizada por meio de um algoritmo de repetição, até que os objetos digitais se esgotem. Inicialmente, identifica-se a informação de conteúdo, posteriormente, a sua informação de representação, caso for necessário, identifica-se a informação de representação adicional, e assim, sucessivamente, formando uma rede de representação complexa.

\subsection{INFORMAÇÃO DESCRITIVA DE PRESERVAÇÃO}

A informação de conteúdo necessita de informações adicionais para sua compreensão durante longos períodos. Logo, esse conjunto específico de objetos de informação é chamado de informação descritiva de preservação (preservation description information - PDI).

Assim, a PDI deve incluir todas as informações necessárias para preservar adequadamente a informação de conteúdo em que está associada. Sua função é, especificamente, descrever os estados passados e presentes da informação de conteúdo, garantir sua identificação única, e que não tenha sido alterada de forma desconhecida (ABNT, 
2007; CCSDS, 2012; ISO 14721:2012). Além da PDI estar relacionada à preservação, identifica-se convergências com as funções de descrição e acesso.

Nessa perspectiva, a descrição possibilita que as informações sobre séries e documentos tornem-se acessíveis (BELLOTTO, 2006). Ressalta-se aqui a pertinência do arquivo ter instrumentos de pesquisa adequados a fim de facilitar o acesso aos consumidores (LOPEZ, 2002). Sendo assim, descrição e acesso são funções arquivísticas que estão implicitamente relacionados ao modelo OAIS, especialmente na forma de PDI, a qual possui quatro categorias, assim definidas:

a) Informação de referência: identifica e caso necessário irá descrever os mecanismos utilizados para fornecer identificadores para as informações de conteúdo. Também fornece identificadores para os sistemas externos referenciarem as informações de conteúdo sem ambiguidades;

b) Informação de contexto: documenta as relações das informações de conteúdo com o seu ambiente. Isto inclui o motivo de sua produção e a forma como se relaciona com os outros objetos de informação de conteúdo existentes em outro local;

c) Informação de proveniência: documenta o histórico da informação de conteúdo, relata sua fonte/origem e a sua cadeia de custódia. Dessa forma, fornece trilhas de auditoria contendo quaisquer alterações proferidas desde a origem, demonstrando assim, confiabilidade aos usuários;

d) Informação de fixidez: fornece verificações de integridade dos dados ou chaves de validação/verificação usadas para garantir que o objeto de informação de conteúdo não tenha sido alterado de forma não documentada. Além disso, pode incluir esquemas de detecção de erro para os objetos de informação de conteúdo. Entretanto, a informação de fixidez não inclui mecanismos para preservação da integridade, no entanto poderá especificar os requisitos mínimos a serem fornecidos pelos serviços de apoio (ABNT, 2007; CCSDS, 2012; ISO 14721:2012).

Observa-se que a taxonomia permite classificar e facilitar o acesso à informação. Assim, é possível alocar, recuperar e comunicar informações em um sistema, de forma lógica e sem ambiguidades. Logo, melhora a interação entre o público interno e externo (LUZ, 2010). Assim, no âmbito da PDI, a informação de referência possibilita identificar a 
informação de conteúdo de forma precisa, sem ambiguidades, de modo a facilitar a sua compreensão seja nas atividades voltadas à preservação seja no acesso oferecido a comunidade designada (público externo ao repositório).

É preciso ir além dos ambientes e equipamentos tecnológicos modernos, e direcionar a atenção para a adequada reunião e ágil localização dos documentos (PAES, 2004). Ou seja, antes de se preocupar com as especificidades dos sistemas de acesso é preciso garantir a reunião dos componentes necessários à correta representação do documento, manter sua integridade, proveniência e organicidade.

No contexto dos documentos arquivísticos, a organicidade é uma das principais diferenças em relação aos demais registros informacionais (SANTOS, 2012). Os documentos arquivísticos estabelecem relações entre si, conforme são produzidos e acumulados, de modo que formam um conjunto de relações que não deve ser separado (SOUSA, 2009).

Sendo assim, a informação de contexto, presente na PDI demonstra a possibilidade de relacionar os objetos de informação custodiados por um repositório digital em conformidade com o OAIS. A informação de contexto confere organicidade aos objetos de informação, o que torna possível a manutenção desse princípio elementar aos documentos arquivísticos digitais.

\begin{abstract}
Os documentos estabelecem relações no decorrer do andamento das transações para as quais foram criados; os documentos estão ligados por um elo que é criado no momento em que são produzidos ou recebidos, que é determinado pela razão de sua criação e que é necessário à sua própria existência, à sua capacidade de cumprir seu objetivo, ao seu significado e sua autenticidade; os registros arquivísticos são um conjunto indivisível de relações (JARDIM; FONSECA, 2008, p. 126).
\end{abstract}

A proveniência dos documentos arquivísticos pode ser entendida como um princípio de classificação natural, um atributo essencial ao conjunto que será dividido. Com isso, é possível garantir a identidade, o sentido e a capacidade de compreender o conjunto documental visto que possui características delimitadas pelo seu acumulador e pelas suas relações orgânicas internas (SOUSA, 2009). A conformidade com o princípio da proveniência constitui o fundo do arquivo, de modo que sejam considerados os conjuntos documentais em vez de um documento isolado. Isto evita a dispersão e garante a integridade administrativa dos documentos arquivísticos (ROUSSEAU; COUTURE, 1998). Ou seja, os documentos individuais, perdem sua expressão organizacional e funcional, quando são retirados de forma arbitrária do seu contexto (SCHELLENBERG, 2006). 
O local da custódia tem a finalidade manter o vínculo arquivístico entre os documentos e garantir a sua segurança. Com isso, poderão ser acessados enquanto documentos autênticos, e consequentemente, servir como fonte de prova ou referência (SILVA, 2016). Observa-se que há uma estreita relação entre a proveniência e a organicidade, e tal relação, é amparada pela custódia. Ou seja, uma custódia confiável irá proteger os documentos de uma determinada proveniência e, ao evitar sua dispersão, estará contribuindo para manter a organicidade dos conjuntos documentais.

Dessa forma, a informação de proveniência irá manter o histórico da informação de conteúdo, contemplando a sua origem e a custódia documental, de modo que seja possível manter a conformidade com o princípio arquivístico da proveniência; além de registrar ações de preservação, como as migrações de dados, e questões relacionadas à propriedade intelectual dos objetos digitais.

A fixidez é a qualidade de um documento arquivístico que assegura a forma fixa e o conteúdo estável. Isto significa que o documento arquivístico digital deve manter a mesma apresentação. Ou seja, consiste na estabilidade, presente de maneira implícita e explícita, no conceito de documento arquivístico, conforme sua conotação arquivística ou diplomática (RONDINELLI, 2013). No entanto, o documento arquivístico em ambiente digital tende a não apresentar fixidez, logo, torna-se necessário garanti-la. A fixidez é uma das características que mais impactam na percepção humana, ao se considerar o fato da confiabilidade (SANTOS, 2012).

O suporte de registro da informação garante a fixidez para documentos analógicos, entretanto, para os documentos digitais a preservação do suporte deixou de ser um requisito para sua manutenção em longo prazo. Antagonicamente, o suporte necessita de uma mudança constante e periódica para manter o documento acessível (SANTOS, 2015).

Dessa forma, a informação de fixidez é um tipo de PDI essencial para preservação e manutenção da autenticidade dos documentos arquivísticos digitais. Logo, podem-se usar ferramentas de checksum ou assinaturas digitais para assegurar que o objeto de informação de conteúdo não foi alterado de forma arbitrária.

Igualmente, com o e-Arq Brasil percebe-se que há metadados relacionados à preservação que já devem ser inseridos já na gestão, dos quais se destacam, por exemplo: identificadores dos componentes digitais, características técnicas, formato de arquivo, mídia/local armazenamento, ambiente de hardware/software, relação com outros 
componentes digitais, fixidez, migrações, replicação e verificação de vírus (BRASIL, 2011). Nessa perspectiva observa-se a compatibilidade entre o OAIS e o e-Arq, obtendo PDI, de modo que a preservação digital começa ser pensada antes mesmo da submissão dos documentos ao repositório.

Em resumo, o OAIS terá de definir com precisão, a informação de conteúdo, para assegurar que possui a PDI necessária para preservá-la de forma adequada. Por meio da PDI é possível reunir informações pertinentes ao processo de preservação e garantia de autenticidade em longo prazo.

\subsection{INFORMAÇÃO DE EMPACOTAMENTO}

A informação de empacotamento (information packaging) relaciona logicamente os componentes de um pacote em uma entidade identificável ou em uma mídia específica. No entanto, sua preservação no OAIS é considerada facultativa.

Observa-se que a informação de empacotamento não contribui para a informação de conteúdo nem para a PDI, logo não há necessidade de preservá-la. Entretanto, há casos em que será necessário reproduzir a submissão original com exatidão, sendo assim, a informação de conteúdo precisará incluir todos os bits que foram previamente submetidos (ABNT, 2007; CCSDS, 2012; ISO 14721:2012).

Assim, o OAIS também deve manter a PDI ou a informação de conteúdo nas conversões de estruturas de nomes dos diretórios/arquivos de dados. Estas estruturas possuem maior tendência para serem utilizadas como informação de empacotamento. Ressalta-se que a informação de empacotamento não é preservada por todas as migrações digitais. Qualquer informação salva em estruturas de nomes de arquivos/diretórios poderá ser perdida quando a informação de empacotamento é alterada (ABNT, 2007; CCSDS, 2012; ISO 14721:2012).

A informação de empacotamento é um recipiente que envolverá o objeto de informação de conteúdo (documento arquivístico digital), sua respectiva informação de representação (metadados associados) e a sua PDI, em uma unidade ou em um pacote de informação identificável. Tal ação é semelhante a uma estratégia de encapsulamento, que busca reunir todas as informações necessárias para correta representação de um determinado documento. 
É aconselhável que os componentes digitais sejam autodescritos e encapsulados, com todas as informações necessárias, em estruturas físicas ou lógicas. Com isto, estima-se garantir que o documento tenha a máxima independência em relação ao ambiente tecnológico no qual foi criado, de modo que possa ser decodificado e compreendido no futuro em diferentes plataformas tecnológicas (SANTOS, 2012; SAYÃO, 2010b).

Desse modo, a informação de empacotamento pode incluir o nome do objeto de informação, o formato, os detalhes de qualquer codificação específica, bem como, a estrutura do volume da mídia de armazenamento. Logo, a informação de empacotamento deve ser considerada na migração de informações para novas mídias de armazenamento (ABNT, 2007; CCSDS, 2012; ISO 14721:2012).

\subsection{INFORMAÇÃO DESCRITIVA}

A informação descritiva (descriptive information) é uma especialização do objeto de informação que fornece recursos adequados para permitir que os consumidores localizem informações de interesse potencial, posteriormente, analisem essas informações, e por fim, solicitem a informação desejada. Além disso, contém dados que são utilizados como entradas (instrumentos chaves) para documentos ou aplicações.

A informação descritiva é geralmente derivada da informação do conteúdo e da PDI. Ela pode ser entendida como um índice que permite acessar o pacote de informação associado, de forma mais eficiente, por meio de instrumentos de acesso. Estes instrumentos podem ser documentos ou aplicações usados para localizar, analisar, recuperar ou solicitar informações armazenadas no OAIS (ABNT, 2007; CCSDS, 2012; ISO 14721:2012).

Essencialmente, a informação descritiva irá detalhar o conteúdo contido no pacote de informação. Dessa forma, irá adicionar precisão ao processo de busca e recuperação da informação, e consequentemente, a comunidade designada localizará a informação de conteúdo desejada mais facilmente. O objeto de informação de conteúdo (documento arquivístico digital), sua informação de representação (metadados) e sua PDI são envolvidos em um pacote de informação, o qual recebe uma informação descritiva, para facilitar a sua localização pela comunidade designada.

Destaca-se que a Norma Brasileira de Descrição Arquivística (NOBRADE) poderá contribuir de forma pertinente no processo de busca dos documentos, e assim, fornecer 
informações como, por exemplo: nível de descrição, história administrativa/arquivística, âmbito e conteúdo, sistema de arranjo, condições de acesso/reprodução, pontos de acesso e indexação de assuntos (BRASIL, 2006). Com isso, observa-se um ponto de complementação entre OAIS e NOBRADE tendo em vista as funções de descrição e acesso. Ademais, elementos como a história administrativa/arquivística oferecem informações para assegurar o registro da proveniência e da custódia, do mesmo modo que o sistema de arranjo corrobora com a manutenção do princípio da organicidade.

No decorrer do trabalho arquivístico, há um duplo objetivo: preservar os documentos e torná-los acessíveis (SCHELLENBERG, 2006). Logo, a função básica dos arquivos consiste em disponibilizar as informações contidas no acervo (PAES, 2004). Neste sentido, a informação descritiva pode ser localizada por meio de ferramentas de busca, e consequentemente, permitir a recuperação da informação de conteúdo (documento arquivístico).

\section{CONSIDERAÇÕES FINAIS}

Este estudo partiu da premissa inicial de que a preservação de documentos digitais em longo prazo necessita da implementação de políticas, estratégias e repositórios em conformidade com o modelo OAIS. Logo, buscou-se traçar uma relação entre o modelo lógico da informação arquivada no OAIS e a sua aplicabilidade no âmbito da Arquivística. Para isso, foram perpassadas questões relativas ao objeto de dados, ao objeto de informação, a informação de representação e a taxonomia das classes de objetos de informação.

A primeira relação abordada no modelo lógico da informação arquivada se refere a transformação do objeto de dados em objeto de informação. Observou-se que ao interpretar a sequência de bits do objeto digital obtém-se o objeto de dados, assim, a informação de representação irá adicionar significado e facilitar a compreensão do objeto de dados. Por consequência, obtém-se um objeto de informação, denominado de objeto de informação de conteúdo, e que é o alvo da preservação digital; o qual simboliza o documento arquivístico digital no ambiente OAIS.

O objeto de informação de conteúdo é obtido a partir da reunião do objeto de dados (objeto físico ou digital) e da informação de representação (metadados). Logo, os sistemas 
informatizados de gestão devem assegurar a manutenção dos objetos digitais e seus respectivos metadados, para posteriormente, submetê-los ao repositório digital. Assim, o repositório em conformidade com o OAIS poderá arquivar o documento arquivístico digital e os seus respectivos metadados que são considerados essenciais para recuperar e compreender o seu conteúdo.

Além da informação de conteúdo e da informação de representação, podem existir outros tipos de objetos de informação no OAIS, dentre eles: PDI, informação de empacotamento e informação descritiva. Tais objetos de informação são essenciais à preservação de documentos em longo prazo.

Na PDI existem quatro subtipos: informação de referência, informação de contexto, informação de proveniência e informação de fixidez. A informação de referência possibilita que a comunidade designada localize a informação de conteúdo desejada por meio de identificadores. A informação de contexto identifica a relação entre as informações de conteúdo, ou seja, a organicidade dos documentos arquivísticos. A informação de proveniência mantém um histórico da custódia da informação de conteúdo, e assim, identifica a origem dos documentos e quaisquer alterações realizadas. $\mathrm{E}$ a informação de fixidez fornece mecanismos para verificar a integridade das informações de conteúdo.

A informação de empacotamento envolve a informação de conteúdo, a informação de representação e a PDI em pacote de informação. Esse pacote pode ser entendido como um objeto encapsulado que contém as informações necessárias para correta representação do objeto de informação de conteúdo (documento arquivístico).

Já a informação descritiva auxilia na localização do pacote de informação ao descrever o seu conteúdo. Além disso, é possível implementar instrumentos de acesso capazes de recuperar a informação descritiva e assim, localizar o pacote que contém as informações desejadas.

De maneira geral, o modelo lógico da informação arquivada no OAIS fornece uma sólida estrutura informacional para a preservação de documentos arquivísticos digitais. Observa-se a consonância com princípios como manutenção da integridade, organicidade, proveniência, além de facilitar o acesso à comunidade designada. Dessa forma, é possível observar uma convergência entre as práticas de preservação digital e os requisitos necessários para manter os documentos arquivísticos autênticos. Tal relação, entre o OAIS e a Arquivística, torna possível a implementação de um repositório arquivístico digital confiável, 
o qual será dotado de competências para preservar e garantir o acesso contínuo em longo prazo a documentos arquivísticos digitais autênticos.

Por fim, este estudo contribuiu para uma aproximação entre a Arquivística e o modelo OAIS, em especial, o modelo lógico da informação arquivada. Dessa forma, a referida comparação colabora para: facilitar a absorção de conhecimento dos pesquisadores recéminiciados na temática; e reforçar a discussão em torno da necessidade de se pensar a preservação digital desde as fases iniciais. A principal limitação do estudo consiste em abordar, tão somente, o plano teórico, sendo assim, sugerem-se novos trabalhos, como, por exemplo, um estudo de caso para relatar as peculiaridades, do modelo lógico da informação arquivada, na implementação de um repositório arquivístico. 


\section{REFERÊNCIAS}

ALMEIDA, M. B.; CENDÓN, B. V.; SOUZA, R. R. Metodologia para implantação de programas de preservação de documentos digitais a longo prazo. Encontros Bibli: Revista Eletrônica de Biblioteconomia e Ciência da Informação, v. 17, n. 34, p. 103-130, maio./ago., 2012. Disponível em: https://doi.org/10.5007/1518-2924.2012v17n34p103. Acesso em 11 nov. 2019.

ASSOCIAÇÃO BRASILEIRA DE NORMAS TÉCNICAS (ABNT). NBR 15472:2007. Sistemas espaciais de dados e informações - Modelo de referência para um sistema aberto de arquivamento de informação (SAAI). Rio de Janeiro: ABNT, 2007.

BARBEDO, F. Arquivos digitais: da origem à maturidade. Cadernos BAD: Revista da Associação Portuguesa de Bibliotecários, Arquivistas e Documentalistas. n. 2, p. 6-18, 2016. Disponível em: https://www.bad.pt/publicacoes/index.php/cadernos/article/view/810. Acesso em: 11 nov. 2019.

BELlotTo, H. L. Arquivos permanentes: tratamento documental. 4. ed. Rio de Janeiro: Editora FGV, 2006.

BODÊ, E. C. Preservação de acervos documentais eletrônicos: desafio além da climatologia e do acondicionamento. Revista Brasileira de Arqueometria, Restauração e Conservação. Olinda, v. 1, n. 2, 2007, p. 32-35. Disponível em: https://www.academia.edu/24890316/. Acesso em: 11 nov. 2019.

BRASIL. CONSELHO NACIONAL DE ARQUIVOS. Câmara Técnica de Documentos Eletrônicos. Carta para a preservação do patrimônio arquivístico digital. Rio de Janeiro: Arquivo Nacional, 2004. Disponível em: http://conarq.arquivonacional.gov.br/images/publicacoes_textos/Carta_preservacao.pdf.

Acesso em: 11 nov. 2019.

BRASIL. CONSELHO NACIONAL DE ARQUIVOS. Câmara Técnica de Documentos Eletrônicos. Diretrizes para a presunção de autenticidade de documentos arquivísticos digitais. Rio de Janeiro: Arquivo Nacional, 2012. Disponível em: http://conarq.gov.br/images/publicacoes_textos/conarq_presuncao_autenticidade_completa.pd f. Acesso em: 11 nov. 2019.

BRASIL. CONSELHO NACIONAL DE ARQUIVOS. Câmara Técnica de Documentos Eletrônicos. Diretrizes para a implementação de repositórios arquivísticos digitais confiáveis - RDC-Arq. Rio de Janeiro: Arquivo Nacional, 2015. Disponível em: http://www.conarq.gov.br/images/publicacoes_textos/diretrizes_rdc_arq.pdf. Acesso em: 11 nov. 2019.

BRASIL. CONSELHO NACIONAL DE ARQUIVOS. Câmara Técnica de Documentos Eletrônicos. e-ARQ Brasil: Modelo de Requisitos para Sistemas Informatizados de Gestão Arquivística de Documentos. Rio de Janeiro: Arquivo Nacional, 2011. 
BRASIL. CONSELHO NACIONAL DE ARQUIVOS. Câmara Técnica de Normalização da Descrição Arquivística. Norma Brasileira de Descrição Arquivística (NOBRADE). Rio de Janeiro: Arquivo Nacional, 2006.

CASANOVAS, I. Gestión de archivos electrónicos. Buenos Aires: Alfagrama, 2008.

CONSULTATIVE COMMITTEE FOR SPACE DATA SYSTEM (CCSDS). Reference model for an Open Archival Information System (OAIS). Magenta Book. Washington, Jun. 2012. Disponível em: https://public.ccsds.org/pubs/650x0m2.pdf. Acesso em: 11 nov. 2019.

DAY, M. Preservation metadata. In: GORMAN, G. E.; DORNER, D. G. (Eds.) Metadata applications and management. International Yearbook of Library and Information Management. London: Facet Publishing. p. 253-273. Disponível em: http://www.ukoln.ac.uk/metadata/publications/iylim-2003/. Acesso em: 11 nov. 2019.

DE SORDI, J. O. Administração da informação: fundamentos e práticas para uma nova gestão do conhecimento. São Paulo: Saraiva, 2008.

FERREIRA, M. Introdução à preservação digital: conceitos, estratégias e actuais consensos. Portugal: Escola de Engenharia da Universidade do Minho, 2006. Disponível em: https://repositorium.sdum.uminho.pt/bitstream/1822/5820/1/livro.pdf. Acesso em: 11 nov. 2019.

GRANGER, S. Emulation as a Digital Preservation Strategy. D-Lib Magazine, v. 6, n. 10, 2000. Disponível em: http://www.dlib.org/dlib/october00/granger/10granger.html. Acesso em: 11 nov. 2019.

GIL, A. C. Como elaborar projetos de pesquisa. 4. ed. São Paulo: Atlas, 2010.

HEDSTROM, M. Digital preservation: a time bomb for digital libraries. Computer and the humanities, Netherlands, n. 31, p. 189-202, 1998. Disponível em: http://deepblue.lib.umich.edu/bitstream/2027.42/42573/1/10579_2004_Article_153071.pdf. Acesso em: 11 nov. 2019.

HEDSTROM, M. Digital preservation: problems and prospects. University of Michigan, Michigan, 2001. Disponível em: http://www.dl.slis.tsukuba.ac.jp/DLjournal/No_20/1hedstrom/1-hedstrom.html. Acesso em: 11 nov. 2019.

INNARELLI, H. C. Instrumenta 2: Preservação de Documentos Digitais. Associação dos Arquivistas de São Paulo. São Paulo: ARQ-SP, 2012a.

INNARELLI, H. C. Preservação digital: a gestão e a preservação do conhecimento explícito digital em instituições arquivísticas. Revista de Ciência da Informação e Documentação, Ribeirão Preto, v. 3, n. 2, p. 48-63, jul./dez. 2012b. Disponível em: https://doi.org/10.11606/issn.2178-2075.v3i2p48-63. Acesso em: 11 nov. 2019.

INNARELLI, H. C. Preservação digital e seus dez mandamentos. In: SANTOS, V. B. (Org.). Arquivística: temas contemporâneos, classificação, preservação digital, gestão do conhecimento. 3. Ed. Distrito Federal: SENAC, 2009, p. 21-75. 
INNARELLI, H. C. Preservação digital: a influência da gestão dos documentos digitais na preservação da informação e da cultura. Revista Digital de Biblioteconomia e Ciência da Informação, Campinas, v. 8, n. 2, p. 72-87, jan./jun. 2011. Disponível em: https://doi.org/10.20396/rdbci.v8i2.1934. Acesso em: 11 nov. 2019.

INTERNATIONAL ORGANIZATION FOR STANDARDIZATION. ISO 14721:2012. Space data and information transfer systems: open archival information system - Reference model.

JARDIM, J. M.; FONSECA, M. O. Arquivos. In: CAMPELlO, B.; CALDEIRA, P. T. (Org.). Introdução às fontes de informação. 2. ed. Belo Horizonte: Autêntica Editora, 2008. p. 121-139.

LÉVY, P. As tecnologias da inteligência: o futuro do pensamento na era da informática. 2. ed. São Paulo: Editora 34, 2010.

LOPEZ, A. P. A. Como descrever documentos de arquivo: elaboração de instrumentos de pesquisa. São Paulo: Arquivo do Estado, 2002.

LUNA, S. V. Planejamento de pesquisa: uma introdução. São Paulo: EDUC, 1997.

LUZ, C. Arquivologia 2.0: a informação digital humana. Florianópolis: Bookess, 2010.

MÁRDERO ARELlANO, M. Á. Preservação de documentos digitais, Ciência da Informação, Brasília, v. 33, n. 2, p. 15-27, maio/ago. 2004. Disponível em: http://revista.ibict.br/ciinf/article/view/1043. Acesso em: 11 nov. 2019.

PAES, M. L. Arquivo: teoria e prática. 3. ed. rev. ampl. Rio de Janeiro: Editora FGV, 2004.

RONDINELLI, R. C. O documento arquivístico ante a realidade digital: uma revisão conceitual necessária. Rio de janeiro: Editora FGV, 2013.

ROTHENBERG, J. Avoiding technological quicksand: finding a viable technical foundation for digital preservation. Council on Library and Information Resources, 1999. Disponível em: https://www.clir.org/pubs/reports/rothenberg/. Acesso em: 11 nov. 2019.

ROUSSEAU, J-Y; COUTURE, C. Os fundamentos da disciplina arquivística. Lisboa: Publicações Dom Quixote, 1998.

SANTOS, H. M.; FLORES, D. Estratégias de preservação digital para documentos arquivísticos: uma breve reflexão. Cadernos BAD: Revista da Associação Portuguesa de Bibliotecários, Arquivistas e Documentalistas, Lisboa, 2015a, n. 1, jan./jun., p. 87-101. Disponível em: http://www.bad.pt/publicacoes/index.php/cadernos/article/view/1225. Acesso em: 11 nov. 2019.

SANTOS, H. M.; FLORES, D. Políticas de preservação digital para documentos arquivísticos. Perspectivas em Ciência da Informação, Belo Horizonte, v. 20, n. 4, p. 197217, out./dez. 2015b. Disponível em: http://dx.doi.org/10.1590/1981-5344/2542. Acesso em: 11 nov. 2019. 
SANTOS, H. M.; FLORES, D. Preservação de documentos arquivísticos digitais: reflexões sobre o uso de padrões abertos nos acervos. Investigación Bibliotecológica: Archivonomía, Bibliotecología e Información, Cidade do México, v. 32, n. 74, p. 35-53, 2018. Disponível em: http://dx.doi.org/10.22201/iibi.24488321xe.2018.74.57905. Acesso em 11 nov. 2019.

SANTOS, V. B. A Arquivística como disciplina científica: princípios, objetivos e objetos. Salvador: 9Bravos, 2015.

SANTOS, V. B. Gestão de documentos eletrônicos: uma visão arquivística. 2. ed. Brasília: Abarq, 2005.

SANTOS, V. B. Preservação de documentos arquivísticos digitais. Ciência da Informação, Brasília, v. 41 n. 1, p.114-126, jan./abr. 2012. Disponível em: http://revista.ibict.br/ciinf/article/view/1357. Acesso em: 11 nov. 2019.

SARAMAGO, M. L. Metadados para preservação digital e aplicação do modelo OAIS. In: CONGRESSO NACIONAL DE BIBLIOTECARIOS, ARQUIVISTAS E DOCUMENTALISTAS, 8., 2004. Anais eletrônicos... Estoril: [s. n.], 2004. Disponível em: http://www.bad.pt/publicacoes/index.php/congressosbad/article/view/640/637. Acesso em: 11 nov. 2019.

SARAMAGO, M. L. Preservação digital a longo prazo: boas práticas e estratégias. Cadernos BAD: Revista da Associação Portuguesa de Bibliotecários, Arquivistas e Documentalistas, Lisboa, n. 2, p. 54-68, 2002. Disponível em: http://www.bad.pt/publicacoes/index.php/cadernos/article/view/866. Acesso em: 11 nov. 2019.

SAYÃO, L. F. Repositórios digitais confiáveis para a preservação de periódicos eletrônicos científicos. Ponto de Acesso, Salvador, v. 4, n. 3, p. 68-94, dez. 2010a. Disponível em: http://www.portalseer.ufba.br/index.php/revistaici/article/view/4709. Acesso em: 11 nov. 2019.

SAYÃO, L. F. Uma outra face dos metadados: informações para a gestão da preservação digital. Encontros Bibli: Revista Eletrônica de Biblioteconomia e Ciência da Informação, Florianópolis, v. 15, n. 30, p.1-31, 2010b. Disponível em: https://periodicos.ufsc.br/index.php/eb/article/view/1518-2924.2010v15n30p1. Acesso em: 11 nov. 2019.

SCHÄFER, M. B.; CONSTANTE, S. E. Políticas e estratégias para a preservação da informação digital. Ponto de Acesso, Salvador, v. 6, n. 3, p. 108-140, dez. 2012. Disponível em: http://www.portalseer.ufba.br/index.php/revistaici/article/view/6449. Acesso em: 11 nov. 2019.

SCHELLENBERG, T. R. Arquivos modernos: princípios e técnicas. 6. ed. Rio de Janeiro: Editora FGV, 2006.

SILVA, E. L.; MENEZES, E. M. Metodologia da pesquisa e elaboração de dissertação. 4. ed. rev. atual. Florianópolis: UFSC, 2005. Disponível em: https://projetos.inf.ufsc.br/arquivos/Metodologia_de_pesquisa_e_elaboracao_de_teses_e_diss ertacoes_4ed.pdf. Acesso em: 11 nov. 2019. 
SILVA, M. O arquivo e o lugar: custódia arquivística e a responsabilidade pela proteção aos arquivos. Niterói: Eduff, 2016.

SMITH, A. Digital preservation research and developments. Russian Digital Libraries Journal, [S.1.], v. 3, n. 3, 2000. Disponível em: https://elbib.ru/ru/article/77. Acesso em: 11 nov. 2019.

SOUSA, R. T. B. A classificação como função matricial do que-fazer arquivístico. In: SANTOS, V. B. (Org.). Arquivística: temas contemporâneos, classificação, preservação digital, gestão do conhecimento. 3. ed. Brasília: SENAC, 2009, p. 79-172.

SOUZA, A. H. L. R.; OLIVEIRA, A. F.; D’AVILA, R. T.; CHAVES, E. S. S. O modelo de referência OAIS e a preservação digital distribuída. Ciência da Informação, Brasília, v. 41, n. 1, p. 65-73, jan./abr., 2012. Disponível em: http://revista.ibict.br/ciinf/article/view/1352. Acesso em: 11 nov. 2019.

THIBODEAU, K. Overview of technological approaches to digital preservation and challenges in coming years. In: COUNCIL ON LIBRARY AND INFORMATION RESOURCES. The state of digital preservation: an international perspective. Washington, D.F., 2002, p. 4-31. 20 Disponível em: http://citeseerx.ist.psu.edu/viewdoc/summary?doi=10.1.1.89.3273. Acesso em: 11 nov. 2019.

THOMAZ, K. P. Repositórios digitais confiáveis e certificação. Arquivística.net, Rio de janeiro, v. 3, n. 1, p. 80-89, jan./jun. 2007. Disponível em: http://www.brapci.inf.br/_repositorio/2010/05/pdf_fed0720dbb_0010726.pdf. Acesso em: 11 nov. 2019.

THOMAZ, K. P. Gestão e preservação de documentos eletrônicos de arquivo: revisão de literatura - parte 2. Arquivística.net, Rio de Janeiro, v.2, n.1, p.114-131, jan./.jun. 2006. Disponível em: http://www.brapci.inf.br/index.php/article/view/0000003988/bb2cabd823d3068f4d817793e6a 11b68. Acesso em: 11 nov. 2019.

THOMAZ, K. P.; SOARES, A. J. A preservação digital e o modelo de referência Open Archival Information System (OAIS). DataGramaZero, v. 5, n. 1, 2004, Rio de Janeiro. Disponível em: http://www.brapci.inf.br/index.php/article/view/0000007749/6f3e125671cfe45b7fddce5de6cf 37f8/. Acesso em: 11 nov. 2019. 